\title{
ANALISIS DETERMINAN LAMA RAWAT INAP PASIEN STROKE DI RUMAH SAKIT UMUM DAERAH KLUNGKUNG MENGGUNAKAN ANALISIS KESINTASAN
}

\author{
Luh Putu Kartika Darmapadmi *, I Ketut Tangking Widarsa, Ketut Hari Mulyawan \\ Program Studi Sarjana Kesehatan Masyarakat Fakultas Kedokteran Universitas Udayana \\ *email: kartikadarmapadmi@gmail.com
}

\begin{abstract}
ABSTRAK
Lama rawat inap merupakan faktor utama yang mempengaruhi beban biaya pasien stroke rawat inap. Penelitian ini bertujuan untuk mengidentifikasi faktor penentu lama pasien rawat inap di RSUD Klungkung tahun 2016. Penelitian ini menggunakan desain kohort retrospektif. Metode total sampling yang digunakan dalam pemilihan sampel dan 149 pasien stroke yang dipilih dirawat di RSUD Klungkung pada 2016. Data sekunder dikumpulkan dengan meninjau rekam medis dari file sampel. Analisis dilakukan dengan menggunakan analisis survival dengan metode Kaplan-Meier dan Cox Regression. Hasil menunjukkan bahwa rata-rata lama rawat inap di antara pasien stroke adalah 9 hari. Rata-rata lama rawat inap di antara pasien stroke dengan diabetes mellitus, komplikasi medis selama rawat inap dan stroke hemoragik adalah 7 (CI 95\%: 6 - 8) hari, 11 (CI 95\%: 7 - -) hari dan 15 (CI 95\%: 14 - 17) hari. Diabetes mellitus, komplikasi medis dan jenis stroke adalah faktor yang mempengaruhi lama rawat inap di antara pasien stroke dengan $\mathrm{HR}=1,82$ (CI 95\%: 1,09 - 3,06), HR =2,73 (CI 95\%: 1,36 - 5,46) dan HR = 3,52 (CI 95\%: 1.89 - 6.57). Berdasarkan jenis stroke, diabetes mellitus berpengaruh signifikan terhadap lama rawat inap di antara pasien stroke iskemik dan hemoragik dengan HR =1,74 (CI 95\%: 1,01 - 2,99) dan HR = 2,26 (CI 95\%: 5,78 - 8,87). Sementara itu, komplikasi medis memiliki efek signifikan di antara pasien stroke iskemik hanya dengan $\mathrm{HR}=2,65$ (CI 95\%: 1,24 - 5,68). Penentu utama yang mempengaruhi lama rawat inap di antara pasien stroke di RSUD Klungkung adalah diabetes mellitus, komplikasi medis dan jenis stroke. Dianjurkan untuk mengontrol faktorfaktor risiko melalui integrasi dengan program Prolanis dan meningkatkan manajemen terutama pada pasien stroke hemoragik untuk mempersingkat lamanya tinggal dan penurunan angka kematian.
\end{abstract}

Kata Kunci : Kecenderungan, Lama Rawat Inap, Stroke, RSUD Klungkung

\begin{abstract}
The length of stay is a major factor affecting the cost burden of inpatient stroke patients. This study aims to identify the determinant of length of stay stroke patient hospitalized at RSUD Klungkung in 2016. This study used a retrospective cohort design. The total sampling method used in sample selection and selected 149 stroke patients hospitalized at RSUD Klungkung in 2016. Secondary data was collected by reviewing medical record of sample file. Analysis was performed using survival analysis by Kaplan-Meier method and Cox Regression. Results showed that the median length of stay among stroke patients was 9 days. The median length of stay among stroke patients with diabetes mellitus, medical complications during hospitalization and hemorrhagic stroke was 7 (CI 95\%: 6 - 8) days, 11 (CI 95\%: 7 - -) days and 15 (CI 95\%: 14 - 17) days. Diabetes mellitus, medical complications and types of stroke are factors that affect the length of stay among stroke patients with $\mathrm{HR}=1.82$ (CI 95\%: $1.09-3.06), \mathrm{HR}=2.73$ (CI 95\%: 1.36 - 5.46) and $\mathrm{HR}=3.52$ (CI 95\%: 1.89 - 6.57). Based on the type of stroke, diabetes mellitus had significant effect on the length of stay among ischemic and hemorrhagic stroke patient with HR =1.74 (CI 95\%: 1.01 - 2.99) and $\mathrm{HR}=2.26$ (CI 95\%: 5.78 - 8.87). Meanwhile, medical complication had significant effect among ischemic stroke patient only with $\mathrm{HR}=2.65$ (CI 95\%: $1.24-5.68$ ). Major determinan affecting length of stay among stroke patient at RSUD Klungkung was diabetes mellitus, medical complication and type of stroke. It is advisable to control the risk factors through integration with Prolanis programs and improve the management especially in hemorrhagic stroke patient to shorten the length of stay and decreased mortality rate.
\end{abstract}

Keywords : Determinant, Length Of Stay, Stroke, RSUD Klungkung

\section{PENDAHULUAN}

Stroke merupakan penyakit yang memerlukan biaya besar dalam proses perawatan dan rehabilitasi. Lama rawat di rumah sakit merupakan faktor utama yang mempengaruhi beban biaya pasien stroke.
Oleh karena itu, semakin lama rawat inap akan meningkatkan beban ekonomi pasien dan keluarga serta mempengaruhi penggunaan tempat tidur dan mutu pelayanan rumah sakit (Mi et al., 2013). 
Stroke adalah gangguan fungsi otak lokal atau luas yang terjadi secara mendadak dan cepat, berlangsung lebih dari 24 jam dan dapat menyebabkan penderita meninggal karena gangguan di pembuluh darah otak (WHO dalam Supriyadi, 2012). Data Riskesdas (2013) menunjukkan prevalensi stroke di Provinsi Bali sebesar 8,3 per 1.000 penduduk, meningkat dibandingkan tahun 2007 sebesar 6,8 per 1.000 penduduk. Kabupaten Klungkung merupakan salah satu wilayah dengan prevalensi penderita stroke yang cukup tinggi di Provinsi Bali.

Faktor-faktor yang mempengaruhi lama rawat inap pasien stroke di rumah sakit cukup banyak diantaranya umur, jenis kelamin, status pernikahan, tekanan darah (hipertensi), penyakit jantung, diabetes mellitus, kadar kolesterol, komplikasi medis, jenis stroke, lokasi infark atau perdarahan serta volume perdarahan (Mi et al., 2013; Saxena et al., 2016; Arboix et al., 2012; Salihovi et al., 2013). Pengetahuan mengenai determinan lama rawat pasien stroke di rumah sakit diharapkan dapat mengurangi beban ekonomi pasien dan keluarga dan menjadi dasar pengambilan keputusan tata laksana penanganan pasien stroke di rumah sakit. Penelitian mengenai faktor-faktor yang mempengaruhi lama rawat pasien stroke di rumah sakit belum banyak dilakukan di Indonesia termasuk di RSUD Klungkung. Oleh karena itu, dalam artikel ini akan dibahas mengenai gambaran lama rawat inap pasien stroke di RSUD Klungkung dan faktor-faktor yang mempengaruhinya.

\section{METODE}

Penelitian ini dirancang sebagai kohort retrospektif dengan anggota kohort adalah pasien yang menjalani rawat inap pertama kali dengan diagnosa stroke di RSUD Klungkung tahun 2016. Pengumpulan data dilakukan pada bulan Maret-April 2017 dengan menelaah berkas rekam medis pasien stroke pertama yang menjalani rawat inap pada Januari-Desember 2016.

Pengambilan sampel dilakukan menggunakan total sampling. Data yang dikumpulkan meliputi tanggal masuk dan keluar rawat inap, jenis kelamin, umur, tekanan darah, gula darah, kolesterol total, komplikasi medis, jenis stroke, kesadaran pasien tiba di rumah sakit dan status pasien (end point).

Penghitungan median lama rawat inap dilakukan menggunakan metode analisis kesintasan (Kaplan-Meier), sedangkan analisis faktor yang mempengaruhi lama rawat inap menggunakan Regresi Cox. Jenis kelamin, umur, tekanan darah, gula darah, kolesterol total, komplikasi medis, jenis stroke dan kesadaran pasien sebagai variabel bebas sedangkan lama rawat inap sebagai variabel tergantung.

\section{HASIL}

\section{Karakteristik Sampel}

Hasil analisis menunjukkan bahwa sebagain besar pasien (96,03\%) berumur $\geq$ 45 tahun. Frekuensi pasien laki-laki dan perempuan seimbang serta $79,47 \%$ pasien tergolong hipertensi pada pemeriksaan pertama ketika tiba di rumah sakit. Sebanyak $15,89 \%$ pasien mengalami diabetes mellitus dan 19,87\% hiperkolesterol. Selama menjalani rawat inap, $10,60 \%$ pasien mengalami komplikasi medis. Lebih dari 70\% merupakan pasien stroke iskemik dan $12,58 \%$ pasien tiba di rumah sakit dengan skor GCS $\leq 7$. 


\section{Lama Rawat Inap Pasien Stroke}

Median lama rawat inap seluruh pasien stroke pertama di RSUD Klungkung tahun 2016 adalah 9 hari. Median lama rawat inap pasien berumur $<45$ tahun adalah lebih panjang dibandingkan pasien berumur $\geq 45$ tahun. Pasien dengan diabetes mellitus (DM) memiliki median rawat inap yang lebih pendek dibandingkan tidak DM sedangkan pasien stroke yang mengalami komplikasi medis selama rawat inap memiliki median lama rawat yang lebih panjang dibandingkan yang tidak mengalami komplikasi. Pasien stroke hemoragik memiliki median rawat inap lebih panjang dibandingkan pasien stroke iskemik sedangkan pasien dengan skor GCS $\leq 7$ memiliki median rawat inap lebih panjang dibandingkan pasien dengan skor GCS > 7. Data hasil analisis dengan Kaplan-Meier dapat dilihat pada tabel 1.

\section{Determinan Lama Rawat Inap Pasien}

\section{Stroke}

Faktor yang mempengaruhi lama rawat inap pasien stroke ditentukan melalui Hazard Ratio (HR) masing-masing variabel. Pada penelitian ini DM, komplikasi medis selama rawat dan jenis stroke merupakan faktor yang mempengaruhi lama rawat inap pasien stroke. Pasien stroke dengan DM memiliki risiko sembuh atau pulang dengan indikasi medis 1,82 kali lebih cepat dibandingkan pasien yang tidak mengalami DM dengan nilai p 0,023 (95\% CI: 1,09 - 3,06). Pasien dengan komplikasi medis memiliki risiko sembuh atau pulang dengan indikasi medis 63\% kali lebih lama dibandingkan pasien tanpa komplikasi medis dengan nilai $\mathrm{p}$ 0,005 (95\% CI: 0,18 - 0,73). Pasien stroke hemoragik memiliki risiko sembuh atau pulang dengan indikasi medis $72 \%$ lebih lama dibandingkan pasien stroke iskemik dengan nilai $\mathrm{p}<0,0001$ (95\% CI: 0,15-0,53). Hasil analisis multivariat dapat dilihat pada tabel 2.

\section{Determinan Lama Rawat Inap}

berdasarkan Jenis Stroke

Ditinjau dari jenis stroke, DM merupakan variabel yang berpengaruh terhadap lama rawat inap pasien stroke iskemik dan hemoragik sedangkan komplikasi medis selama rawat hanya mempengaruhi lama rawat inap pasien stroke iskemik. Pasien stroke iskemik dengan DM berisiko pulang dengan indikasi medis 1,73 lebih cepat dibandingkan tanpa DM dengan nilai $\mathrm{p}$ 0,047 (95\% CI: 1,00 - 2,98), sedangkan pada pasien stroke hemoragik dengan DM berisiko pulang dengan indikasi medis 2,26 kali lebih cepat dibandingkan tanpa DM dengan nilai $\mathrm{p}<0,001$ (95\% CI: 5,78 - 8,87). Pada pasien stroke iskemik dengan komplikasi medis selama rawat berisiko mengalami pulang dengan

Tabel 1. Lama Rawat Inap Pasien Stroke di RSUD Klungkung tahun 2016 (n=151)

\begin{tabular}{lcccc}
\hline Determinan & $\begin{array}{c}\text { Median Lama } \\
\text { Rawat Inap } \\
\text { (hari) }\end{array}$ & $\begin{array}{c}\text { Batas } \\
\text { Bawah }\end{array}$ & Batas Atas & Nilai p \\
$\begin{array}{l}\text { Seluruh pasien } \\
\text { Umur } \\
\bullet<45 \text { tahun }\end{array}$ & 9 & & & \\
\hline
\end{tabular}


- $\geq 45$ tahun

Jenis kelamin

- Perempuan

- Laki-laki

Hipertensi

- Normal

- Hipertensi

Diabetes mellitus (DM)

- Tidak DM

- DM

Hiperkolesterol

- Tidak hiperkolesterol

- Hiperkolesterol

Komplikasi medis selama rawat inap

- Tidak

- Ya

Jenis stroke

- Iskemik

- Hemoragik

Kesadaran pasien
9

9

9

9

9

10

7

9

9

8

10

-

(

$$
10
$$


- $<45$ tahun (baseline)

- $\geq 45$ tahun

Jenis kelamin

- Perempuan (baseline)

- Laki-laki

0,90

0,60

1,36

0,628

Hipertensi

- Normal (baseline)

- Hipertensi

1,12

0,68

1,84

0,660

Diabetes mellitus

- Tidak DM (baseline)

- DM

1,82

1,09

3,06

$0,023^{*}$

Hiperkolesterol

- Tidak hiperkolesterol (baseline)

- Hiperkolesterol

0,97

0,60

1,56

0,886

Komplikasi medis selama rawat inap

- Tidak (baseline)

- Ya

0,37

0,18

0,73

$0,005^{*}$

Jenis stroke

- Iskemik (baseline)

- Hemoragik

0,28

0,15

0,53

$<0,0001^{*}$

Kesadaran pasien

- GCS $>7$ (baseline)

- $\mathrm{GCS} \leq 7$

0,49

0,18

1,29

0,149

Kondisi ini dapat terjadi karena pasien dengan umur lebih tua hanya sedikit yang mengikuti pemulihan atau rehabilitasi pasca serangan walaupun memiliki tingkat disabilitas yang lebih tinggi. Pasien dengan usia lebih tua umumnya mendapatkan perawatan pasca serangan lebih banyak di luar rumah sakit (Bhalla et al., 2004). Pada penelitian ini, umur tidak berpengaruh terhadap lama rawat inap pasien stroke. Hasil yang sama juga ditemukan oleh Saxena et al. (2016) pada penelitian terhadap pasien stroke di India.

Pasien dengan kondisi kehilangan kesadaran berat (skor GCS $\leq 7$ ) memiliki median rawat inap yang lebih lama dibandingkan pasien dengan kondisi kehilangan kesadaran ringan (skor GCS > 7). Lamanya rawat inap pasien dengan skor GCS rendah disebabkan oleh perburukan klinis yang berkaitan dengan gagal nafas akibat gangguan langsung pada kontrol respirasi di batang otak maupun komplikasi sistemik seperti pneumonia, emboli dan edema pulmo (Zazulia, 2009). Pada penelitian ini skor GCS tidak berhubungan dengan lama rawat inap pasien stroke.

DM merupakan salah satu faktor yang mempengaruhi lama rawat pasien 
stroke dalam penelitian ini. Median lama rawat inap pasien stroke yang mengalami DM lebih cepat dibandingkan pasien yang tidak mengalami DM. Hasil penelitian ini berbeda Al-Eithan et al. (2011) dan Appelros (2007) yang menyebutkan bahwa pasien stroke dengan DM memiliki rawat inap yang lebih lama. Median rawat inap pasien stroke dengan DM yang lebih cepat kemungkinan disebabkan karena penatalaksanaan diabetes pada pasien stroke rawat inap telah diterapkan dengan baik melalui pemeriksaan dan kontrol gula darah secara rutin sehingga dapat mencegah komplikasi yang dapat menghambat perbaikan klinis pasien stroke (Golden et al., 2005). Penelitian ini juga menunjukkan bahwa DM mempengaruhi lama rawat inap pada pasien stroke iskemik maupun hemoragik. Peningkatan lama rawat inap pasien stroke iskemik dengan DM terjadi berhubungan dengan glikosuria yang menyebabkan poliuria. Hilangnya cairan bersama urine menyebabkan darah mengalami kepekatan, menjadi trombosis dan menyebabkan aterosklesrosis yang meningkatkan penyempitan pembuluh darah ke otak. Selain itu, DM meningkatkan risiko infeksi dan komplikasi seperti pneumonia dan infeksi saluran kemih (Nakagawa et al., 2014). Sedangkan pada pasien stroke hemoragik, Song et al. (2003) menyebutkan bahwa kadar gula darah yang tinggi menyebabkan edema dan kematian jaringan di sekitar area perdarahan.

Komplikasi medis selama rawat mempengaruhi lama rawat pasien stroke secara umum dan pasien stroke iskemik. Hasil ini didukung oleh Ingeman et al.
(2011) pada penduduk Denmark. Pneumonia dan infeksi saluran kemih merupakan jenis komplikasi yang paling sering terjadi pada pasien stroke rawat inap. Pneumonia pada pasien stroke akut disebabkan kondisi imunologik yang menurun, pasien tidak dapat batuk dan menelan sehingga cairan terkumpul dalam paru-paru dan menimbulkan gangguan respirasi. Sedangkan infeksi saluran kemih disebabkan oleh penggunaan kateter urine yang dapat menjadi jalur masuk patogen sehingga menjadi sumber infeksi pada aliran darah (Johnsen et al., 2012).

Pasien dengan diagnosa stroke hemoragik memiliki median rawat inap lebih lama dibandingkan pasien stroke iskemik. Hasil ini selaras dengan penelitian Lee et al. (2008) pada populasi di Taiwan. Pasien stroke hemoragik umumnya memiliki prognosis yang lebih buruk disebabkan masuknya darah ke jaringan otak akan meningkatkan tekanan intrakranial, menyebabkan kerusakan jaringan saraf dan gangguan aliran darah di arteri.

Pada penelitian ini, jenis kelamin tidak terbukti sebagai variabel yang mempengaruhi lama rawat inap pasien stroke. Hasil ini sejalan oleh penelitian Saxena et al. (2016) bahwa jenis kelamin bukan faktor yang berpengaruh secara signifikan terhadap lama rawat pasien stroke. Lama rawat inap pasien stroke umumnya dipengaruhi oleh banyak faktor seperti adanya komplikasi, penyakit penyerta seperti DM, jenis stroke dan status kesadaran pasien. Banyaknya faktor penyerta yang dimiliki pasien akan berperan dalam meningkatkan lama rawat yang diperlukan. Penelitian ini juga menunjukkan tidak ada hubungan antara 
tekanan darah awal masuk dan lama rawat inap. Beberapa penelitian menyebutkan tekanan darah awal masuk yang tinggi dapat menurunkan morbiditas dan mortalitas karena pemantauan tekanan darah yang lebih baik dan dapat membantu pengambilan keputusan terapi yang diberikan sehingga kemungkinan lama rawat menjadi lebih pendek. Saxena et al. (2016) juga menyebutkan hasil yang sama bahwa hipertensi tidak berpengaruh terhadap lama rawat pasien stroke akut. Hiperkolesterolemia dihubungkan dengan risiko aterosklerosis yang apabila tidak terkontrol akan menghambat suplai darah dan oksigen ke otak sehingga menyebabkan perburukan kondisi klinis pasien (Nastiti, 2012). Pada penelitian ini hanya $20,13 \%$ pasien stroke rawat inap yang mengalami hiperkolesterol dan sejalan dengan penelitian Mailisafitri (2011) dan Nastiti (2012) sehingga hiperkolesterol tidak berhubungan dengan lama rawat pasien stroke dalam penelitian ini.

\section{Kelemahan Studi}

Permasalahan yang dihadapi peneliti adalah ketidaklengkapan data rekam medis sehingga beberapa berkas rekam medis tidak dapat digunakan dalam penelitian. Selain itu, peneliti juga tidak dapat menganalisis hubungan lokasi dan volume perdarahan dengan lama rawat inap pasien stroke hemoragik karena informasi tersebut tidak terdapat dalam data rekam medis sehingga faktor yang diduga berpengaruh terhadap lama rawat pasien stroke khususnya stroke hemoragik tersebut tidak dapat diteliti.

\section{SIMPULAN}

Berdasarkan hasil penelitian dapat disimpulkan bahwa median lama rawat inap pasien stroke di RSUD Klungkung tahun 2016 adalah 9 hari dan telah sesuai dengan rata-rata lama rawat pasien stroke pada umumnya. Determinan lama rawat inap pasien stroke di RSUD Klungkung tahun 2016 adalah diabetes mellitus (DM), komplikasi medis selama rawat inap dan jenis stroke. Ditinjau dari jenis stroke, DM mempengaruhi lama rawat inap pasien stroke iskemik maupun hemoragik sedangkan komplikasi medis selama rawat hanya mempengaruhi lama rawat inap pasien stroke iskemik. Kontrol faktor risiko seperti gula darah melalui integrasi dengan program pengelolaan penyakit kronis (prolanis) dan peningkatan pelaksanaan Ct-scan pada pasien stroke hemoragik diharapkan dapat membantu keputusan penanganan klinis lebih cepat sehingga diharapkan dapat menurunkan lama rawat inap dan tingkat mortalitas pasien stroke.

\section{DAFTAR PUSTAKA}

Al-Eithan, M.H., Amin, M., Robert, A.A. (2011). The Effect of Hemiplegia/Hemiparesis, Diabetes Mellitus, and Hypertension on Hospital Length of Stay After Stroke. Neurosciences, 16(3): 253-256.

Appelros P. (2007). Prediction of Length of Stay for Stroke Patients. Acta Neurol Scand, 116: 15-19.

Arboix, A. et al. (2012). Clinical Predictors of Prolonged Hospital Stay after Acute Stroke: Relevance of Medical Complications. 
International Journal of Clinical Medicine, 3: 502-507.

Bhalla, A., Grieve, R., Tilling, K., Rudd, A.G., Wolfe, C.D.A. (2004). Older Stroke Patients in Europe: Stroke Care and Determinants of Outcome. Age and Ageing, 33(6): 618-624.

Golden, S.H., Felicia, H.B., Wiliams, K., Stolka, K., Mayer, R.S. (2005). Management of Diabetes During Acute Stroke and Inpatient Stroke Rehabilitation. Arch Phys Med Rehabil, 86: 2377-2384.

Ingeman, A. et al. (2011). In Hospital Medical Complications, Length of Stay, and Mortality Among Stroke Unit Patients. American Heart Association Journal, 42: 32143218 .

Johnsen, S.P., Svendsen, M.L. \& Ingeman A. (2012). Infection in Patients with Acute Stroke. The Open Infectious Diseases Journal, 6: 40-45.

Lee, H.C., Chang, K.C., Lan, C.F., Hong, C.T., Huang, Y.C., Chang, M.L. (2008). Factors Associated with Prolonged Hospital Stay for Acute Stroke in Taiwan. Acta Neurol Taiwan, 17: 17-25.

Mailisafitri. (2011). Faktor-Faktor yang Berhubungan dengan Kematian pada Pasien Stroke di Instalasi Rawat Inap Rumah Sakit Stroke Bukittinggi Tahun 2010. Skripsi Fakultas Kesehatan Masyarakat Universitas Indonesia.

Mi, S. et al. (2013). Determinants of the Length of Stay in Stroke Patients.
Osong Public Health and Research Perspectives, 4(6): 329-341.

Nakagawa, K. et al. (2014). Impact of Diabetes on Prolonged Hospital Stay among Native Hawaiians and other Pacific Islanders with Ischemic Stroke. Hawai" i Journal of Medicine E Public Health, 73(12): 4-7.

Nastiti, D. (2012). Gambaran Faktor Risiko Kejadian Stroke pada Pasien Stroke Rawat Inap di Rumah Sakit Krakatau Medika Tahun 2011. Skripsi Fakultas Kesehatan Masyarakat Universitas Indonesia. 